\title{
La justificación cientifica y filosófica del respeto hacia la naturaleza: Teilhard de Chardin, Arne Naess y el Papa Francisco
}

\author{
The Scientific and Philosophical Justification of \\ the Respect to Nature. Teilhard de Chardin, Arne \\ Naess and the Pope Francisco
}

\author{
JOSÉ VICO MARTÍN
}

$U N E D$

Recibido: 02/09/2016 Aceptado:16/03/2017

\begin{abstract}
RESUMEN
Tres modelos de sensibilidad ecológico-social son visibles hoy en relación con la naturaleza. El primero, el más atávico, consiste en la indiferencia instintiva. El segundo, algo más elaborado, en su conservación utilitaria. Y el tercero, el más consistente, en el respeto esencial por ella. Y ahí, en el vértice de la jerarquía humana pensante; aislados, pocos, románticos e iluminados, encontramos a unos cuantos personajes que tratan, machaconamente, de expandir un «extraño» mensaje entre el amasijo tecnocientífico actual; el del ecologismo comprometido. Su imperativo es inapelable: somos el único ser vivo del planeta dotado de suficiente autoconsciencia y, por eso mismo, de exigible responsabilidad. Sobre todo, en el caso de que existieran argumentos suficientes que enlacen nuestra estirpe con el resto de los seres vivos de la Tierra. Y ese es el objetivo de este artículo. Teilhard de Chardin, Arne Naess y el papa Francisco son tres de los mejores ejemplos de quienes han contribuido a la justificación científica y filosófica del respeto debido a la Naturaleza. En ellos, centraremos nuestro análisis.
\end{abstract}

BIOSFERA, NOOSFERA, HOMINIZACIÓN, AUTOCONSCIENCIA, PSIQUISMO.

(C) Contrastes. Revista Internacional de Filosofía, vol. XXIII-Nº1 (2018), pp. 93-110. ISSN: 1136-4076 Departamento de Filosofía, Universidad de Málaga, Facultad de Filosofía y Letras Campus de Teatinos, E-29071 Málaga (España) 


\begin{abstract}
Three models of sensitivity relating to Social Ecology are visible today in relation to nature. The first, the most atavistic, consists of the instinctive indifference. The second, something more elaborate, of utilitarian conservation. And the third, the most consistent, of essential respect for her. And there, in the vertex of the thinking human hierarchy: isolated, a few, romantic and illuminated we find several of characters that try, tiresomely, to expand a "strange" message in between a tangled, present techno science; the committed environmentalism. Its imperative is unappealable: we are the only living being in the world gifted with sufficient self-awareness and, for that reason, we have required responsibility. Above all, in the case that there could exist sufficient arguments that link our own lineage with the rest of the living beings on this Earth. And that's the objective of this article. Teilhard de Chardin, Arne Naess, and the Pope Francisco are the three best examples that have contributed to the scientific and philosophical justification of the respect owed to Nature. In them, we focus our analysis.
\end{abstract}

KEYWORDS

BIOSPHERE, NOOSPHERE, HOMINIZATION, SELF-AWARENESS, PSYCHISM

\title{
I. NUESTRA RESPONSABILIDAD
}

LA JUSTIFICACIÓN HISTÓRICA DEL NACIMIENTO DEL ECOLOGISMO COMO filosofía y modelo humano de vida, habría que situarla en los hechos de la experiencia. Solo a medida que las consecuencias de nuestro comportamiento con la naturaleza se han ido haciendo más patentes, hemos caído en la cuenta de nuestros graves errores. Tan aletargada hemos tenido nuestra capacidad anticipatoria, que vamos a necesitar despertarla poniendo a trabajar, a pleno rendimiento, nuestra mejor herramienta, la razón. Pero no la vieja razón, pacata, egoísta y utilitaria a la que estamos acostumbrados, sino una razón nueva, de largo alcance existencial y temporal, mucho más inteligente, y de la que tenemos poca experiencia. Una razón, en suma, que sea capaz de «ver» mucho más allá de nuestra subjetividad material; que se trascienda a sí misma, y que busque su lugar, no en nuestros limitados cuerpos, sino en la unidad universal de la vida. Si el final de los tiempos acaba llegando, que las generaciones futuras, al menos, no tengan que abominar del siglo XXI. Padecemos un déficit importante de percepción. Llevamos demasiado tiempo contemplando el mundo solo desde arriba, cuando lo justo y adecuado hubiera sido mirar mucho más a derecha e izquierda.

Daremos por sentado, entonces, que el lector conoce la delicada situación medioambiental que padecemos y que reconoce, asimismo, la urgente necesidad de las pertinentes acciones correctoras. Así que, en este artículo, se trata de relacionar, en las obras de algunos de sus protagonistas, la defensa enérgica de unos nuevos modelos de interpretación y conocimiento del mundo que nos rodea. Unos modelos capaces de sobresalir por encima de la costra de ego que durante tantos siglos llevamos engrosando sin cesar. El imperativo es 
simple: somos el único ser vivo del planeta dotado de razón y de la suficiente autoconsciencia como para trascender nuestra concreta existencia y abarcar, así, la idea de la unidad total de la vida, por un lado, y distinguir entre conveniencia y valor, por otro.

\section{LOS PRIMEROS ANTECEDENTES.}

$\mathrm{Si}$, desde el solicitado reconocimiento de la crisis ecológica, y en busca de sus orígenes, uno se ocupa en investigar antecedentes intelectuales en defensa de la naturaleza, el ideal biocéntrico más temprano de la historia del ecologismo, en la civilización occidental, es El cántico de las Criaturas compuesto por san Francisco de Asís en el año $1225 .^{1}$

Conviene precisar que lo que refleja el biocentrismo del Cántico de las Criaturas es, en el fondo, la visión teocéntrica de su autor sobre la naturaleza. Francisco de Asís, no podía ser ecologista por la sencilla razón de que en aquellos tiempos la naturaleza no estaba en peligro, ni así se la veía y, por lo tanto, no se planteaba la necesidad de defenderla ni, mucho menos, de buscar argumentos con los que frenar un expolio ambiental que no se percibía como tal. Es verdad, como se sabe, que el expolio sí existía; ${ }^{2}$ pero, a principios del siglo XIII, ante la incomparable y desconocida extensión de la Tierra, los lentos efectos nocivos del hombre pasaban completamente desapercibidos.

Si san Francisco dignificó a animales y plantas; ríos y montañas; Sol, Luna, viento y lluvia, poniéndolos a la altura de los humanos no fue, obviamente, por razones evolutivas o biológicas, que tardarían mucho en llegar. Y si practicó una severa austeridad es imposible que pensara, entonces, en la finitud de los recursos naturales. El «poverello» era precisamente eso, pobre, austero y humilde, porque fue un modelo de coherencia radical. Francisco de Asís empieza su discurso «ecológico» más arriba: el amor a la naturaleza no procede, en él, de un sentimiento de unidad teo-universal al estilo del panteísmo de Spinoza. Para Francisco, la naturaleza no se con-funde con Dios: la naturaleza, con todos nosotros dentro, no es un atributo de Dios; es obra de Dios; procede de Dios; es hija de Dios. Por eso, para el santo, el amor fraternal hacia todo lo que contiene la Tierra no se deriva de una dignidad que se reconociera como intrínseca al mismo planeta - otra forma de fraternidad, por otra parte. El hermano lobo o la hermana Luna lo son porque, junto con

1 Referencia obligada para los fundamentos del ecologismo es, también, la filosofía china del Tao Te Ching del siglo VI a.C.

2 En este sentido se puede consultar: Broswimmer, Franz J., (2005). Ecocidio: breve historia de la extinción en masa de las especies. Pamplona: Editorial Laetoli, S.L.; Deléage, Jean Paul, (1993). Historia de la Ecología. Barcelona: Icaria Editorial, S.A.; y Diamond, Jared, (2006). Colapso: por qué unas sociedades perduran y otras desaparecen. Madrid: Debate. 
él mismo, vienen de mucho más alto; proceden del mismo Padre. Y eso, la perfecta conexión del pensamiento de Francisco de Asís con el Evangelio de su Maestro, es el fundamento de su amor a la naturaleza y de su consecuente vida. Lo cual, por otra parte, no desmerece en nada el valor del medio elegido.

Es tal el grado de coherencia con la literalidad del Evangelio que vale la pena terminar esta breve noticia sobre el santo Patrón de los ecologistas, con dos de sus recomendaciones a sus hermanos de orden: «Cuando los hermanos van por el mundo, nada lleven para el camino, ni bolsa, ni alforja, ni pan, ni pecunia, ni bastón». ${ }^{3}$ "Y aquellos que venían a tomar esta vida, daban a los pobres todo lo que podían tener (Tob 1,3); y estaban contentos con una túnica, forrada por dentro y por fuera, el cordón y los paños menores». ${ }^{4}$

Lamentablemente, y no solo por los cristianos, el hermano lobo y la hermana hierba siguieron siendo masacrado el uno y pisoteada la otra. O los humanos leímos interesadamente el relato de la Creación o, a quienes no lo conocieron, no se les ocurrió nunca pensar, ni siquiera ante tan semejantes criaturas como los grandes simios, que los animales y, por extensión, el resto del mundo natural, pudieran ostentar derechos.

\section{La Ecología Profunda de Arne Naess.}

En el año 1973, el filósofo noruego Arne Naess, publicaba un artículo en el que, bajo el título The Shallow and the Deep, Long-Range ecology movement, ${ }^{5}$ alertaba sobre la insuficiencia de los movimientos ecologistas a los que él llamaba superficiales: los que, con buena intención, pero con corta mirada, abogaban solo por mejorar las políticas conservacionistas de la naturaleza.

Alicia Irene Bugallo, de la Universidad de Buenos Aires y especialista en la obra de Arne Naess, cita en su tesis doctoral lo que ella llama «La primera versión del Movimiento Ecología Profunda; su relación con la ciencia y la sabiduría». Y lo hace así:

En su artículo de 1992, 'The Three Great Movements' ['Los tres grandes movimientos'], Arne Naess destacaba retrospectivamente, cómo, hacia fines del

3 Francisco de Asís. Escritos Completos. Regla no Bulada, p. 58. En: http://www.corazones.org/santos/francisco_asis.htm

4 En: http://www.corazones.org/santos/francisco_asis.htm

5 Naess, Arne (1973). «The shallow and the deep, long-range ecology movement. A summary», Inquiry, 16: 1, 95-100. Disponible en: http://www.wildsreprisal.com/PDF's/ Cascadia\%20Rising/The $\% 20$ shallow $\% 20$ and $\% 20$ the $\% 20$ deep, $\% 20$ long-range $\% 20$ ecology $\% 20$ movement.pdf. Trad. de Ricardo Rozzi y Christopher Anderson en: Revista Ambiente y Desarrollo 23:1 (2007): 98-101. 
siglo XX, se fueron acentuando tres grandes tendencias hacia la auto-destrucción en la sociedad humana:

Primero, la auto-destrucción que provocan las guerras.

Segundo, la auto-destrucción por explotación o eliminación de seres humanos y, finalmente:

La auto-destrucción que implica la supresión de la diversidad de seres no humanos.

E indicaba, además, las reacciones que dichos fenómenos habían provocado. Así:

La tendencia a la beligerancia constante dio lugar al movimiento global por la paz mundial (una de cuyas manifestaciones fue la creación de las Naciones Unidas, terminada la Segunda Guerra Mundial); la falta de respeto por los derechos humanos llevó a la aparición del movimiento mundial por la justicia social (con organizaciones por los derechos humanos o Amnesty Internacional como sus expresiones; [y] finalmente, tendríamos la consolidación de un movimiento mucho más joven de carácter ambientalista, como respuesta a la disminución acelerada de la diversidad biológica y del progresivo deterioro del ambiente planetario. En esta línea se ubicaría el Movimiento Ecología Profunda. ${ }^{6}$

Efectivamente, por primera vez en la historia del ecologismo consciente, alguien trataba de fundamentar y sistematizar, en 1973 y desde la filosofía, los crecientes movimientos en favor de la defensa de la naturaleza. Y, en este sentido, lo primero que había que hacer, era una importante distinción entre quienes entendían la naturaleza solo como un bien económico, y quienes, en cambio, estaban dispuestos a respetarla por su propia esencia. Cada vez para más gente, el mundo natural tenía, tan solo por su misma existencia y al margen del hombre, su propia dignidad y sus propios derechos. Y esa era la concepción a la que Arne Naess llamó, por primera vez, Ecología Profunda. Para la otra, la simple, la instrumental y la utilitaria, reservaría el nombre de Ecología Superficial. Entre esos dos polos, se sitúa el amplio recorrido del pensamiento ecológico al que alude el título de su artículo fundacional The Shallow and the Deep, Long-Range ecology movement.

El sistema de la ecofilosofía naessiana asentaba su estructura en siete principios originales que son -decía- «más bien generalizaciones vagas, que solo se sostienen si se hacen más precisas en ciertas direcciones. No obstante, a través de todo el mundo la inspiración derivada de la ecología ha

6 Bugallo, Alicia Irene (2011). La filosofía ambiental en Arne Naess. Influencias de Spinoza y James, Río Cuarto (Argentina): Ediciones del ICALA (Intercambio Cultural AlemánLatinoamericano), p. 38. 
demostrado convergencias notables. Este análisis no pretende ser más que una de las posibles codificaciones condensadas de estas convergencias ». ${ }^{7}$ Por condicionamiento de espacio resaltamos solo los tres más relevantes:

1 - Rechazar la imagen del hombre-en-el-medio ambiente en favor de la imagen relacional, de campo total [que] considera a los organismos como nudos en la red biosférica o campo de relaciones intrínsecas.

2 - El ecólogo de campo adquiere un respeto profundo, incluso una reverencia por los modos y formas de vida [...]. Para el ecólogo de campo, la igualdad de derecho a vivir y florecer es un axioma de valor intuitivamente claro y manifiesto. Su restricción a los seres humanos es un antropocentrismo con efectos nocivos sobre la calidad de vida de los propios seres humanos.

4 - La diversidad de formas de vida humana se debe en parte (con o sin intención) a la explotación y a la supresión por parte de ciertos grupos [...]. El principio de diversidad no justifica diferencias debidas puramente a actitudes o comportamientos forzadamente bloqueados o restringidos. Los principios de igualdad ecológica y de simbiosis sustentan la misma postura anticlasista. ${ }^{8}$

No es aquí, por su extensión, el lugar adecuado para un análisis pormenorizado de tales modelos y de sus consecuencias ${ }^{9}$. Pero sí conviene añadir, en relación con todos ellos, que, desde el final del XIX, también los Thoreau, los Leopold o los Emerson sintieron esa naturaleza en su espíritu más que analizada en su intelecto. Sus experiencias interiores les llevaron a todos a la consideración ontológica fundamental de la ecología humana: la trascendencia del mundo natural entero hacia una comunión cosmológica.

Al mismo tiempo, no se pueden olvidar, por su influencia, las circunstancias sociales de la segunda mitad del siglo XX, y contra las que nacieron los fundamentos ecológicos expuestos. El mundo occidental estaba en plena ebullición desarrollista. Se demandaban toda clase de electrodomésticos, automóviles, carreteras, aeropuertos y energía, grandes cantidades de energía. ${ }^{10}$ Por eso no es de extrañar, en medio de este panorama, el espanto que transmite Rachel Carson - por poner solo un ejemplo- cuando describe, en su Primavera Silenciosa de 1962, ${ }^{11}$ los desastrosos efectos que sobre la salud humana y no humana tuvieron los pesticidas -sobre todo el DDT-distribuidos

7 Naess, Arne (1973), op. cit., p. 98.

8 Ibid., 99.

$9 C f$. Bugallo, Alicia Irene (2011), op. cit., p. 199 y ss. para consultar una extensa bibliografía al respecto.

10 Puede verse, en este sentido: Illich, Iván (1974). Energía y equidad. Barcelona: Barral Editores, S.A.

11 Carson, Rachel L. (2010). Primavera silenciosa. Barcelona: Editorial Crítica, S.L. 
en masa gracias a la utilización de todos los «ingenios» -aviones incluidosde la tecnología moderna. La propaganda a la que se vieron sometidos los núcleos de población, tanto urbanos como rurales, estaba obteniendo el mayor de los éxitos de manipulación de masas.

\section{El papa Francisco y LaUdato SI’.}

Preocupado por el devenir actual de la humanidad, el papa Francisco, en la primera encíclica ecologista del mundo, hace, en 2015, una declaración importante que, no obstante, no parece haber alcanzado la difusión y el realce que se merece:

Tomé su nombre [el de Francisco de Asís] como guía y como inspiración en el momento de mi elección como Obispo de Roma. ${ }^{12}$

La Encíclica, como se ve, no ha sido pensada como cumplimiento de las tradiciones de los pontífices. Ha sido escrita porque Francisco -el papallevaba ya en sí el mensaje del otro Francisco - el santo- antes de su elección. Por eso, en ecología, ambos personajes no se pueden separar.

Cuando Francisco de Asís alaba a Dios por todas sus criaturas, cabría especular -al menos retóricamente- si el Santo llega a Él por las criaturas o, por el contrario, descubre a las criaturas a través de Dios. Pero, aunque la matización pudiera ser de suma importancia desde la fe religiosa, no lo es, en cambio, desde la filosofía. Y no lo es porque, en cualquiera de los dos sentidos, se requiere la noción de trascendencia. Al fin y al cabo, la sabiduría humana está para eso y en eso consiste; en superar constantemente lo concreto cada vez que generamos algo tan etéreo como una abstracción.

En consecuencia, la introducción comparativa de Laudato $S i$ ' que nos proponemos, no se apoyará sobre el posible origen, creacionista o gnoseológico, de lo que entendemos por Naturaleza. Se limitará, aquí, a las posibles concomitancias filosóficas con las otras dos posiciones aludidas: la que defiende la ecología profunda de Arne Naess y la que Teilhard de Chardin expone en El fenómeno humano.

Esta hermana [la Tierra] clama por el daño que le provocamos a causa del uso irresponsable y del abuso de los bienes que Dios ha puesto en ella. [...] Olvidamos que nosotros mismos somos tierra (cf. Gn 2,7). Nuestro propio cuerpo está constituido por los elementos del planeta, su aire es el que nos da aliento y su agua nos vivifica y restaura. ${ }^{13}$

12 El papa Francisco (2015). Laudato si'. Madrid: Romana Editorial, S.L., p. 15.

13 Ibid.pp. 7-8. 
En las primeras páginas del documento papal, se encuentra la tesis central de nuestro argumentario anterior. Por un lado, coherente con un documento eclesiástico, la referencia a Dios como creador supremo. Y, por otra parte, y al final de la cita, el reconocimiento de nuestro origen cosmológico. Y este es el mensaje principal de Laudato $S i$ ', una elevación conceptual que se dirige a un Dios creador y un sentimiento de comunión con el universo entero.

Con los matices inherentes a épocas muy distintas hay, sin embargo, coincidencia básica entre el papa y Ane Naess en la consideración unitaria de lo que hoy llamaríamos la dinámica terrestre. Lo que este último afirma diciendo que la biosfera es un campo de relaciones en el que cada organismo ejerce la función de nudo de conexión de esas relaciones, ${ }^{14}$ lo redacta y lo matiza así el papa Francisco: «Si bien el cambio es parte de la dinámica de los sistemas complejos [la cursiva es mía], la velocidad que las acciones humanas le imponen hoy contrasta con la natural lentitud de la evolución biológica». ${ }^{15} \mathrm{Y}$, aunque en la villa de Asís nada supieran de ecología, y mucho menos san Francisco, basta con leer su Cántico para coincidir con esta afirmación del papa: «Su discípulo san Buenaventura decía de él que 'lleno de la mayor ternura al considerar el origen común de todas las cosas (de nuevo, la cursiva es mía), daba a todas las criaturas, por más despreciables que parecieran, el dulce nombre de hermanas». ${ }^{16}$ Sistemática y lógicamente trabada, o emocionalmente interiorizada y sentida, resulta evidente que la unión de la biosfera en un todo distinto y superior a las partes, es el arranque común, tanto en la ecología profunda, como en Laudato Si'. Lo que existía ya, nada menos que desde principios del siglo XIII.

Ahora bien, en clave epistemológica-que no instrumental-, la aprehensión de esta totalidad natural, ya sea por la vía de la racionalidad científica, por la intuición emocional, o por representatividad del propio Dios, requiere de la aceptación de distintas formas de conocimiento. De otra manera:

No se puede sostener que las ciencias empíricas explican completamente la vida, el entramado de todas las criaturas y el conjunto de la realidad. [...] Si se reflexiona con ese marco cerrado desaparecen la sensibilidad estética, la poesía y aun la capacidad de la razón para percibir el sentido y la finalidad de las cosas. ${ }^{17}$

La afirmación no es nueva; también así interpretaban la naturaleza los grandes precursores como Leopold, Thoreau o Emerson. Y también, con el

14 Naess, Arne (1973), op. cit., p. 98.

15 Francisco (2015), op. cit. p. 17.

16 Ibid., p. 11.

17 Ibid., pp. 177-178. 
mismo trasfondo, lo hace el segundo principio de la formulación original de la ecología profunda presentado más arriba.

Volviendo, entonces, al argumentario integrador y para no perder la coherencia interna de este trabajo, vale la pena resaltar estas tres premisas: la unidad de la naturaleza; la unidad de su tratamiento epistemológico; y la escala humana del conocimiento y de las políticas sociales, como la expresión concreta de los amplios criterios (epistemológico, ontológico y ético-práctico) con los que estamos abordando las posibles correlaciones entre la Encíclica papal y la Ecología Profunda con la concepción noosférica de Vernadsky, Le Conte y Teilhard de Chardin.

La elección es nuestra: formar una sociedad global para cuidar la Tierra y cuidarnos unos a otros o arriesgarnos a la destrucción de nosotros mismos y de la diversidad de la vida. Se necesitan cambios fundamentales en nuestros valores, instituciones y formas de vida. Debemos darnos cuenta de que, una vez satisfechas las necesidades básicas, el desarrollo humano se refiere primordialmente a ser más, no a tener más. ${ }^{18}$

Porque «también el ambiente social tiene sus heridas. Pero todas ellas se deben en el fondo al mismo mal, es decir, a la idea de que no existen verdades indiscutibles que guíen nuestras vidas, por lo cual la libertad humana no tiene límites». ${ }^{19}$

Con la concordancia de los criterios ontológicos y epistemológicos, tanto de la Ecología Profunda como de la doctrina oficial de la Iglesia Católica, constatamos, como resultado obvio, que los fundamentos metafísicos son diferentes entre ambas concepciones. Mientras la primera los encuentra en un sentimiento humano de trascendencia espiritual y unión cosmológica-los orígenes culturales de Naess-, pero no sobrenatural; el papa los infiere de su $f e$ en un Dios personal que nos llama a una conversión ecológica porque «cada organismo es bueno y admirable en sí mismo por ser una criatura de Dios»». ${ }^{20}$ Una vez más, como se vivía en las históricas sociedades vernáculas, el sentimiento de unión con la naturaleza parece formar parte de lo más esencial del ser humano cualquiera que sea su creencia y práctica religiosa. El acierto de Erns Haeckel llamando «casa común» a la Tierra entera, se ve ahora mucho más que oportuno.

Además de lo dicho, cabría establecer diferencias de matiz e implicaciones de las dos posturas en todos los órdenes; pero, en cualquier caso, ninguna de

18 Carta de la Tierra, la Haya, 29 de junio de 2000. En: www2.uned.es/catedraunescoeducam/CARTADELATIERRA.htm

19 Francisco (2015), op. cit., p.11.

20 Ibid.p. 129. 
las existentes es de la suficiente enjundia como para poner en entredicho los postulados fundamentales. Así es que solo nos resta, para cumplir el triple objetivo que nos habíamos propuesto, analizar, siquiera someramente, las posiciones ético-sociales de ambas doctrinas.

El centro ético de la encíclica Laudato Si' es, en este sentido, claro y contundente;

$[\mathrm{H}]$ oy no podemos dejar de reconocer que un verdadero planteo ecológico, se convierte siempre en un planteo social, que debe integrar la justicia en las discusiones sobre el ambiente, para escuchar tanto el clamor de la tierra como el clamor de los pobres. ${ }^{21}$

Y el clamor al que el papa se refiere no es ninguna exageración: «El dato de que nada menos que 1.300 millones de personas viven aproximadamente con menos de 1 dólar al día [en negrita en el original] nos lo dice todo: el mundo no está bien repartido, y es necesario hacer algo para cambiarlo».22

Es justo resaltar la coherencia entre ecologismo natural y ecologismo social que muestra Laudato $\mathrm{Si}^{\prime}$ :

El impacto de los desajustes actuales se manifiesta también en la muerte prematura de muchos pobres, en los conflictos generados por falta de recursos y en tantos otros problemas que no tienen espacio suficiente en las agendas del mundo. ${ }^{23}$

Pero dejemos, por unos momentos, el relato del ecologismo del papa Francisco, que reanudaremos con mayor coherencia después de las siguientes aportaciones.

\section{La Biosfera: Vladímir IvÁNOVich Vernadsky.}

Insistíamos, unas líneas atrás, en la consideración unitaria de la totalidad de la capa externa de la Tierra como un gran sistema autoorganizado (autorealizado, como matiza Naess) ${ }^{24}$. Nos estamos refiriendo al primer

21 Ibid., p. 48.

22 Manos Unidas, Campaña: Plántale Cara al Hambre, febrero 2016. Disponible en: http://www.manosunidas.org/noticia/manos-unidas-lanza-su-campana-plantale-cara-al-hambresiembra-manosunidassiembra.

23 Conferencia Episcopal Alemana. Comisión para Asuntos Sociales, septiembre 2006. En Laudato Si', p. 47.

24 Naess, Arne (1973), op. cit., p. 99. 
intento sistemático, el de Vladímir Ivánovich Vernadsky, para delimitar científicamente la mayor de las complejidades que la evolución haya podido producir, la vida.

Por sus rasgos intrínsecos, la biosfera puede definirse como una región de la corteza terrestre sembrada de transformadores que convierten las radiaciones cósmicas en energía terrestre activa, energía eléctrica, química, mecánica, térmica, etc. ${ }^{25}$

Esta visión integradora de la naturaleza no era habitual en una época tan ecológicamente temprana como 1926. Como tampoco se había propuesto aún, al menos formalmente, la idea de la intensa transformación geológica que la vida llevaba a cabo desde sus principios. Él es quien lo expone por primera vez:

Es el conjunto de los organismos vivos de la Tierra, la materia viva, la que transforma la energía radiante del sol en energía química de la biosfera (en su forma activa). [...] La materia viva, constantemente y a una velocidad inconcebible, recubre la biosfera con una gruesa capa de sistemas moleculares nuevos, originando fácilmente compuestos distintos, ricos en energía libre en el campo termodinámico de la biosfera. ${ }^{26}$

Sobre estas dos premisas científicas, Vernadsky, aportando suficientes datos experimentales, elabora, por lo que él llama generalización empírica, un auténtico sistema biogeoquímico de relaciones entre su materia viva, y los tres estratos básicos, hidrosfera, litosfera y atmósfera. A los que, casi veinte años después, se añadirá por él mismo, y se fundamentará después por Teilhard de Chardin, otro gran transformador geológico, preconizado ya en 1927 por el matemático francés Edouard Le Roy: el pensamiento.

En efecto, la revista American Scientist, (volumen 33, No 1, enero 1945), publicaba un artículo de Vernadsky con el título de La Biosfera y la Noosfera, y del que nos parece importante citar textualmente su origen histórico:

La Primera Guerra Mundial influyó de forma decisiva en mi propia obra científica, en el sentido de que modificó radicalmente mi noción geológica del mundo. Fue en la atmósfera creada por esa guerra cuando me planteé [...] una concepción geoquímica y biogeoquímica que abarca desde la primera perspectiva tanto la naturaleza viva como la inerte. ${ }^{27}$

25 Vernadsky, Vladimir I., (1997). La biosfera. Madrid: Fundación Argentaria-Visor Dis., p. 60.

26 Ibid., p. 63.

27 Ibid., pp. 210-211. 
$\mathrm{Y}$ en el transcurso de casi veinte años, Vernadsky que, como él mismo declara, fue «exponiendo las conclusiones a las que llegaba en conferencias e informes», toma prestadas (de Darwin, Dana y Le Conte) dos ideas de mitad del siglo XIX que resultan hoy fundamentales para entender el movimiento ecologista: una, que el proceso evolutivo es solamente característico de la materia viva, ${ }^{28} \mathrm{y}$ dos,

[que] la evolución de esa materia viva avanza en una dirección categórica. A este fenómeno lo llamó Dana 'cefalización» y Le Conte «era psicozoica». Al igual que Darwin, Dana adoptó esta idea durante su viaje alrededor del mundo, viaje que inició en 1838, dos años después del regreso de Darwin a Londres, y que duró hasta $1842 .^{29}$

Conviene destacar que la expresión «dirección categórica» que Vernadsky utiliza, no se refiere a una supuesta linealidad u ortogénesis del proceso evolutivo que estuviera guiada por ninguna misteriosa fuerza interior. El sabio ruso - materialista radical, por otra parte- trata, por lo que se colige del contexto total del libro en el que está escrita, de resaltar la enorme trascendencia que la concentración del sistema nervioso en una protuberancia capital, tiene para la vida animada.

Dana subrayó que, en el transcurso del tiempo geológico, durante al menos dos mil millones de años y probablemente mucho más, tiene lugar un proceso irregular de crecimiento y perfeccionamiento del sistema nervioso central, empezando por los crustáceos (cuyo estudio utilizó Dana para demostrar su principio), siguiendo por los moluscos (cefalópodos) y terminando por el hombre. A este fenómeno es al que denominó cefalización. ${ }^{30}$

El avance hacia la hominización resultante alcanzará su culminación y su síntesis en la inteligencia humana, porque «una vez que llega a cierto nivel en el proceso evolutivo, el cerebro no está sometido a retroceso alguno, sino que únicamente puede seguir progresando». ${ }^{31}$ Las consecuencias de tal afirmación van a ser decisivas. Porque la teoría lleva implícita que, como los humanos siempre vivimos en compañía, desde ese momento «los intereses de las masas, por un lado, y el libre albedrío de los individuos, por otro, determinan el curso vital de la humanidad y proporcionan estándares para las ideas humanas de 
justicia» ${ }^{32}$; lo que plantea a Vernadsky la necesidad de la «reconstrucción de la biosfera en interés de la humanidad librepensadora como totalidad». ${ }^{33}$

Curiosamente, esta brillante historia científica destila un hilo de decepción; el siguiente paso, el que pudo conducir a la síntesis final entre la era psicozoica de Le Conte y la biosfera del propio Vernadsky, no acertó a darlo este último. Tuvo que ser un matemático y filósofo francés el que siguiera la senda iniciada por los principios de la biogeoquímica del geólogo ruso y propusiera, en 1927 y como culminación del camino evolutivo de la materia viva ${ }^{34}$ de Vernadsky, el concepto de Noosfera. Una idea que Edouard Le Roy, el matemático y filósofo al que nos referíamos, había elaborado a lo largo de multitud de conversaciones con su gran amigo y compatriota, el paleontólogo y filósofo Pierre Teilhard de Chardin que lo explica así en una carta dirigida a Claude Cuénot el 1 de diciembre de 1954:

Nos veíamos todos los miércoles por la tarde. Y por aquella época redacté un largo artículo sobre la Hominización (no recuerdo exactamente el título) que, Le Roy, creo, cita en alguna parte a pie de página (o al menos señala) en L'exigence idéaliste. ${ }^{35}[\ldots][\mathrm{H}]$ e recogido la influencia de Le Roy en mis artículos, después. El término «hominización» existía antes que yo, lo encontré en un artículo publicado hacia 1920 por un antropólogo alemán (¿Von Eckstedt?). Pero creo que fue en este ensayo en que aparece por primera vez la palabra (y la noción) de Noosfera, que fue afortunada, gracias a Le Roy y al sabio ruso Vernadsky (que estaba entonces en París). ${ }^{36}$

El caso es que, si fue un matemático transformado en filósofo el que fundiera las nociones de cefalización de Dana con los tiempos psicozoicos de Le Conte en una síntesis noosférica, eso pudo ser el precio pagado por la reticencia del propio Vernadsky a considerar como saber válido «el concepto de 'vida' [que] excede siempre los límites del de 'materia viva'; [y que]

32 Ibid., p. 215.

33 Ibid., pp. 215-216.

34 «El concepto de "vida" [dice Vernadsky] excede siempre los límites del de "materia viva"; pertenece al reino de la filosofía, el folklore, la religión y las artes. Todo esto se encuentra excluido de la noción de «materia viva». Ibid. P. 212.

35 Teilhard se refiere a la obra de Le Roy, Edouard (1927). L'exigence idéaliste et le fait de l'évolutión, París: Boivin \& Cie.

36 En Leandro Sequeiros, Manuel Medina y María José Medina, Facultad de Teología de Granada y François Euvé, Facultés Jésuites de París: Las Cartas Inéditas de Teilhard de Chardin a Édouard Le Roy: Más luces sobre el conflicto entre ciencia, filosofía y teología. Pensamiento, vol. 65 (2009), núm. 246, pp. 1077-1098. 
pertenece al reino de la filosofía, el folklore, la religión y las artes. Todo esto se encuentra excluido de la noción de 'materia viva». ${ }^{37}$

Como se aprecia, el sabio ruso no consideraba como vía de conocimiento fiable más que la ciencia positiva. Y, si se mira bien, la ironía del caso es cómo algo tan poco científico como los valores humanos se le «cuela» al materialismo cientificista de Vernadsky llegando, incluso, a dar la impresión de que mete en el mismo saco a categorías tan dispares como el espíritu y la materia.

A partir del concepto del papel geológico del hombre, el geólogo A. P. Pavlov (1845-1929) solía hablar en los últimos años de su vida de la era antropogénica en la que vivimos hoy en día. Aunque no tuvo en cuenta la posibilidad de la destrucción de los valores espirituales y materiales [sic] a que asistimos actualmente con la bárbara invasión de los alemanes y sus aliados poco más de diez años tras su muerte, resaltó con razón que el hombre se está convirtiendo ante nuestros propios ojos en una fuerza geológica poderosa y en permanente crecimiento. $^{38}$

Con las anteriores anotaciones, esta reducida introducción está llegando a su fin (mucho más por limitaciones de espacio que por su potencialidad); un fin, empero, que puede antojarse como un tanto inesperado; y se verá por qué.

\section{Teilhard de Chardin y El fenómeno humano.}

La historia del pensamiento ecológico occidental sitúa sus primeros balbuceos en el período romántico americano de finales del siglo XIX; llega, desde ahí, a su nacimiento formal en la década de los sesenta del XX; y, de pronto y en un inexplicable salto de treinta años, se olvida completamente del tiempo comprendido entre 1920 y 1950. Cabría pensar, ante esa circunstancia, que el proceso de la ecologización humana tuviera que derivarse de las más recientes ideas elaboradas al amparo de los últimos avances científicos. Pero eso no es así, al entender de quien esto escribe.

Resulta que Pierre Teilhard de Chardin, el 28 de octubre de 1948 en Roma, firma un libro, El Fenómeno Humano, en el que después de afirmar que «el Hombre es el más misterioso y el más desconcertante de los objetos descubiertos por la Ciencia...[que] no ha encontrado todavía para él un lugar

37 Vernadsky, Vladímir I. (1997), op. cit. p.212.

38 Ibid., p. 214. 
en sus representaciones del Universo», ${ }^{39}$ se molesta en plantearse esa rareza partiendo de la constatación empírica del proceso de hominización:

Salto morfológico ínfimo y al mismo tiempo increíble conmoción de las esferas de la Vida, toda la paradoja humana... Y, por consiguiente, evidencia absoluta de que, en sus reconstrucciones del Mundo, la Ciencia desdeña un factor esencial, o por mejor decir, una dimensión entera del Universo. ${ }^{40}$

Y ahí, en el olvido de que el universo, incluso por su propia etimología, no se puede parcelar ni en el más minúsculo de sus componentes, radica el origen de nuestros males ecológicos y humanos y, por ende, la esencia y la justificación argumental máxima de los movimientos ecologistas. Esa es la convergencia que buscábamos, y de la que solo nos faltaba su justificación empírica. Y esa pudiera haber sido, también, la base epistemológica que condujo a Teilhard y a Le Roy a postular, ya en los años veinte, una fuerza tan abarcadora y poderosa como su idea de la noosfera; la envoltura más elevada y de mayor poder transformador de la Tierra, el intelecto. El mismo Teilhard lo proponía así en la obra citada:

[P]ara asignar al Hombre su situación natural en el Mundo experimental, es necesario y suficiente que hagamos entrar en juego el Interior al propio tiempo que el Exterior de las cosas. ${ }^{41}$

Así pues, la justificación del pensamiento ecológico había sido ya encontrada mucho antes de que la segunda mitad del siglo XX y su desbordamiento capitalista y tecnocrático, pusiera en estado de alerta a las capas mejor pensantes del planeta. Hasta entonces, la noosfera parecía estar en estado latente. Sus más básicos componentes, el pensamiento individual y la reflexión, trataban de abrirse paso hacia la autoconsciencia a través de la maraña de los instintos. Y este es el camino histórico-intelectual que sistemáticamente, etapa geológica a etapa geológica, recorre el paleontólogo francés.

Teilhard de Chardin sigue, de este modo y con científicos pasos, el implacable avance de la vida desde su mínima organización e imperceptible psiquismo, la célula, hasta la expresión máxima de su complejidad; la consciencia, el hombre. En el trayecto, y en sus últimos pasos geológicos, la reflexión, «el saber que se sabe» y no el «simple saber» -en sus propias palabras- determina la grandeza máxima del «paso decisivo en el que se

39 Teilhard de Chardin, P. (1974). El Fenómeno Humano. Madrid: Taurus Ediciones S.A., p. 197, p.199.

40 Ibid., p. 199.

41 Ibid., p. 200. 
encuentra empeñada hoy en día la Humanidad en marcha»: $:^{42}$ la hominización del individuo ha dado comienzo. Así que,

Si la historia de la vida no es, como hemos dicho, sino un movimiento de consciencia velado de morfología, es inevitable que, hasta la cumbre de la serie, en las inmediaciones del Hombre, los psiquismos [significativamente así, en plural] se presenten y aparezcan a flor de inteligencia. Que es precisamente lo que ocurre. Y con ello es la «paradoja humana» la que se esclarece. ${ }^{43}[\ldots]$ Con la «persona», dotada por la «personalización» de un poder indefinido de evolución elemental, la rama cesa de llevar en su conjunto anónimo las promesas exclusivas del porvenir. La célula se ha hecho «alguien». Después del grano de Materia, después del grano de Vida, he aquí, al fin, constituido el grano de pensamiento. ${ }^{44}$

En este transcurso, la expansión de la vida en su continuo devenir, se encargará del resto; el jesuita-científico-filósofo lo llama el paso filético; la hominización de la especie. Y, adivinar el final del proceso debería ser, ahora, cosa fácil. Teilhard, nos ha conducido hasta el umbral del presente y, en estas favorables condiciones, tan solo nos falta poner en práctica nuestra recién estrenada condición humana. Pero eso es cosa nuestra y va a ser la principal responsabilidad y ocupación ética del hombre. Porque el aura noosférica de la humanidad que, a estas alturas, debería ya rodear intensamente una Tierra en la culminación de su era psicozoica, reverbera, todavía hoy, de forma inconsistente cuando «para un marciano capaz de analizar tanto psíquica como físicamente las radiaciones siderales, la primera característica de nuestro planeta sería ciertamente la de aparecerle no ya azulado por sus mares, o verdeante por sus bosques, sino fosforescente de Pensamiento». ${ }^{45}$

Volver ahora al papa Francisco puede resultar, después de la ontología noosférica de Teilhard de Chardin, mucho más esclarecedor. El pontífice no hace otra cosa en su encíclica (y no es poco, dada la ignorancia generalizada), que recordarnos que, desde que estrenamos aquella condición humana, no hemos estado a la altura de lo que la vida -la que Teilhard, al menos, defiendese merece. El papa, como corresponde, lo achaca a nuestro ensoberbecimiento científico causante del actual alejamiento de Dios y de la falta de respeto hacia su Obra. Pero es que resulta que el jesuita francés argumenta su tesis de la hominización colectiva con metodología científica y no teológica. Así que, en buena lógica, la reprimenda -también científica, además de moralpor nuestros desvaríos con la naturaleza, y sobre todo con el prójimo, está

42 Ibid., pp. 201-202.

43 Ibid., p. 204.

44 Ibid., p. 211.

45 Ibid., p. 222. 
justificada sean cuales fueren los principios vitales desde los que se parta. La noosfera abarca la totalidad de la actividad pensante y, por eso mismo, la totalidad de sus contenidos. Incluidos, naturalmente, también los estéticos:

Cuando alguien no aprende a detenerse para para percibir y valorar lo bello, no es extraño que todo se convierta para él en objeto de uso y abuso inescrupuloso. ${ }^{46}$

Seguir actuando como una «invasión biológica de un tipo animal nuevo que elimina o esclaviza gradualmente a toda forma de vida que no sea la humana» $;{ }^{47}$ y hasta a su propia especie -añadimos-es una tremenda deslealtad para la completa población viva de la Tierra.

\section{CONCLUSIONES}

No es infrecuente que, enfrascados en una cierta trama literaria, los lectores hayamos olvidado el título con el que el autor quiso enmarcar su texto. De modo que permítaseme la advertencia por si este fuera el caso aquí. El subtítulo de este artículo presenta tres corrientes de pensamiento en el orden histórico en el que se sucedieron; la primera, del primer cuarto del siglo XX, la segunda en la década de los setenta, y la última, del año 2015. Total, noventa años de historia de la vida.

En el desarrollo ofrecido, en cambio, el pensamiento del científico ruso Vernadsky y de Pierre Teilhard de Chardin -los primeros, cronológicamente-, no aparecen sino al final del texto. Y la razón no es caprichosa. Porque resulta que la historia del pensamiento ecológico no ha hecho justicia con ninguno de los dos; por eso aparecen en último lugar. Lo que este autor ha pretendido con eso, es poner de relieve cómo, con un saber unificado -que todavía hoy no se practica-, los vericuetos teológicos, románticos y filosóficos utilizados para revestir de legitimidad a los movimientos de defensa de la naturaleza, se hubieran visto fuertemente simplificados y más fácilmente aceptados, con la comprobación científica de la unidad de la naturaleza que esos dos grandes personajes habían ofrecido ya desde el año 1926. El primero, con su concepción biogeológica del planeta Tierra y el segundo, a través de la paleontología. La Biosfera y El fenómeno humano, como queda dicho, son sus obras maestras.

Tres han sido, por otra parte, las pretensiones principales de este breve análisis comparativo que acabamos de ofrecer:

La primera, mostrar que la ciencia, la filosofía y la religión son perfectamente compatibles entre sí para argumentar sólidamente en favor de lo que más debería importar hoy a la humanidad entera: el respeto máximo a

46 Francisco, papa; op. cit., p. 163.

47 Teilhard de Chardin, P., op. cit., p. 222. 
la totalidad de la naturaleza y, por extensión, a los derechos sociales de todos nuestros semejantes. Lo que, dado el carácter básico y el amplísimo dominio de estas tres formas de conocimiento, es un hito importante en la historia y expansión del pensamiento ecológico. También el arte, por cierto, se muestra cada vez más respetuoso con la vida en general, y con el medio ambiente, en particular. Solo por razones de espacio no se ha incluido aquí.

La segunda intención, ha sido la de comprobar la validez y la consiguiente oportunidad de aplicación, de las tres premisas establecidas unas páginas atrás: la unidad de la naturaleza; la unidad de su tratamiento epistemológico; y la escala humana del conocimiento y de las prácticas sociales. Las tres han sido defendidas, con mayor o menor incidencia específica, por cada uno de nuestros protagonistas.

Y el tercero de los objetivos -y no menos importante- que este autor se había propuesto, consiste en una noticia histórica que el ecologismo, o no conoció, o nunca cayó en la cuenta de su importancia: la existencia, al menos desde los años treinta, de la teoría de la hominización de Teilhard de Chardin. Un caso particular del proceso de cefalización, y que es un poderoso y uno de los más tempranos y completos argumentos ecológicos en favor de la concepción unitaria de la naturaleza. En particular, del origen común del hombre con el resto de los seres vivos del planeta. Incluida la consciencia, de cuya existencia gradual en muchos otros animales no humanos no cabe ya ninguna duda. ${ }^{48}$

José Vico Martín es licenciado en Filosofía y Ciencias de la Educación y doctorando de la UNED.

\section{Lineas de Investigación:}

La superación del conservacionismo utilitario de la naturaleza por una validación científica y filosófica del pensamiento ecológico

Correo electrónico: vico.martin@hotmail.com

48 Un aspecto sorprendente más de esta historia olvidada de la justificación científica y filosófica de la unidad de la naturaleza, estriba en el hecho -tampoco señalado en los ambientes ecologistas- de que, en el año 1979, un filósofo español de la talla de José Ferrater Mora publicara un libro, De la materia a la razón, en el que se recorre el mismo trayecto ontológico que, treinta años antes, había ocupado la mente de Teilhard de Chardin. Lástima que el espacio de un artículo no permita un análisis pormenorizado de tales circunstancias que, este autor, sí está desarrollando en otro formato. 